\title{
Becoming (a) Practice ${ }^{1}$
}

By Kjersti Bjørkeng, Stewart Clegg, Tyrone Pitsis,

CMOS, School of Management, Faculty of Business

University of Technology, Sydney

PO Box 123 Broadway NSW 2007, Australia

\footnotetext{
${ }^{1}$ We would like to acknowledge the kind sponsorship of the Australian Research Council through the ARC Linkage Project grant (project number LP0348816). We also acknowledge the contribution and involvement of our industry partners; their openness and honesty throughout the research project have been an exemplary basis for research collaboration. Helpful comments on the paper were provided by Arne Carlsen, Roger Klev and Kristian Kreiner as well as by the reviewers.
} 


\begin{abstract}
This paper presents findings from longitudinal ethnographic research of a mega-project alliance. For five years we followed the leadership team of a large Australian Alliance Program made up of several private and a large public organization, analyzing 'practice' as novel patterns of interaction developed into predictable arrays of activities, changing and transforming while at the same time continuing to be referred to as "the same". In this paper we focus on three such arrays of activities; authoring boundaries, negotiating competencies and adapting materiality. We suggest that these are essential mechanisms in becoming a practice. While most studies of practice deal with already established practices, the significance of our research is that we develop a notion of practice as it unfolds. In this way we can provide a better account of the constant change inherent in practices.
\end{abstract}

Keywords: practice, project management, alliancing, construction. 


\section{Introduction}

From being a rather specialized and restricted analytical term in use in 1970s Marxist circles, when the Althusserian notion of 'theoretical practice' was briefly popular (Althusser 1969), 'practice' is taking on a new meaning in analytic discourse in contemporary social science. Practice is now presented as a primary generic social fact (Schatzki, 2001), one which will enable us to explain other social phenomena, such as knowledge, meaning, science, power, language, life worlds, institutions and roles, structures, and systems. Some practice theories follow Marxist tradition in holding that understanding human action requires an analytic focus on the entire social and historical context of that action, particularly contributions from cultural and historical activity theory and actor network theory (Munro, 2008). Nicolini et al. (2003) remind us that practice theorists owe Marx recognition that practice signifies both our production of the world and the result of this production process.

While Marxists argue that one can be mistaken about what one is practicing, Schütz (1967) would not agree: members' accounts have analytic primacy. Ontologically practice is seen to concern the 'how and why' of all human activity; as Schütz (1967) argued, no practice can be understood outside its intersubjectively created meaning and motive, which, as we have known since Mills (2002/1940), Wittgenstein (1953), and as Blum and McHugh (1971), are socially reinforced, constructed and ascribed. Practice, particularly in the context of work, is thus a key term for signifying how we achieve active being-in-the-world. The influence of Schütz on ethnomethodology (Garfinkel 
1967) enabled its analysts to make a move similar to Wittgenstein; specific contextual understanding of practices becomes the tacit resource that makes sense possible. The phenomenological idea that knowing in practice can occur prior to reflexive theoretical knowledge of that practice, as well as being what makes this knowledge possible, is thus highlighted. That is, all experience and the tools we use to make sense of experience are intersubjectively constructed; in social science, the most useful will translate into and from lay terms; Schütz recommends that all analytic constructs should, in principle, be capable of back-translation to the ordinary members' sense of what they are doing. Thus, on this conception, any general idea of practice would be grounded ontologically in everyday knowledge and action.

While practice theory is a field with multiple personalities, as divergent as it is convergent, most practice theories hold that:

1. Practices are embodied arrays of activities organized around a shared practical understanding or "way of doing" (although the question of whether or not the analyst and subject share understanding is unclear.)

2. Understandings of practice require the apprehension of the specific practice's material configurations. Such apprehension can be grasped by reference to context and to a meta-theory that grasps that context as such-and-such a context, but also, in an ethnomethodological tradition, by reference to the immediate material settings and intersubjective understandings of the activities explored.

3. Specific practices reduce the scope and ordering power of a disembodied, asocial and acontextual (Cartesian) concept of reason by re-conceptualizing reason as a 
practice phenomenon; hence, as in Garfinkel (1967), rationality ceases to be an analytic category and, instead, should be seen as a grounded member's category grounded in what members find it normal to do. Thus, practice defines its own rationality, the upshot of Garfinkel's (1967) analysis of the correct rules that jurors respect.

4. The field which practice addresses concerns the total nexus of interconnected human practices; practice is everything - and thus nothing - as nothing falls outside of practice and everything falls within it. Hence, the focus has to be on particular practices in order to have substantive specificity.

5. Social order, however conceived, is to be found in the field of practices, both established by it and establishing it. Practices are recursive; through the sense that they deploy they shape the sense of that which is in order and that which is not.

Nicolini et al (2003) extend these ideas to the field of practice in organization studies by emphasizing a characteristic practice based vocabulary, stressing active verbs such as strategizing, knowing, and becoming (as did Weick 1995 before them). The practice based vocabulary is filled with gerunds. Gerunds are verbal nouns, doing words, expressing generalized or uncompleted action, and are used to signify how practices are always in the making, always becoming and evolving. Describing practices as always becoming entails treating change as a normal condition of practicing; activities performed are always situated and thus always novel. Nevertheless; even if change is the normal condition of practice, this does not entail that practices are always changing (Tsoukas and Chia, 2002). 
The majority of organizational studies of practice begin their enquiries from established practices: haute cuisine (Gomez, Bouty and Drucker-Godard, 2003); flute making (Yanow, 2003); construction of safety (Gherardi and Nicolini, 2003), and bridge-building (Suchman, 2003), to name but a few. These practices are typified by a sense of shared materiality, however conceived, which is already present. In each case the practice was sufficiently established, embedded and organized that its practitioners knew how to go on; in principle and in practice they knew how they were doing what they were doing and, just as important, when they were doing it wrong.

While acknowledging that all practices are essentially becoming, some features of becoming may be more evident when one is researching a novel practice that is not yet established. While the starting point of our investigation was interorganizational collaboration, at the end of our longitudinal research we found ourselves in the midst of something that could be analysed as "a practice". To capture a practice in its slow, longitudinal processes of coming to be, to follow organizing as it evolves and morphs from a set of established practice(s) to create something new, is a rare opportunity: Contrary to conventions in practice based studies, our research did not assume shared understanding, shared habits or shared skills, or invoke phenomena such as goals or propositional knowledge to understand practice. On the contrary, through our research the intersubjective processes of construction and reconstruction of these phenomena are emphasised, to suggest that fluidity and adaptability in these phenomena are essential for becoming (a) practice. 


\section{Methodology}

\section{The Case}

We explore material drawn from research conducted since 2002 into a large Alliance Program of construction, an alliance designed to spread risk and responsibility as well as to pool resources (Clegg et.al. 2008, Pitsis et al 2004; Pitsis et al, 2003; Clegg et al, 2002). The alliance was a Public-Private Partnership with an estimated duration of eight years and an AUD\$383 million target cost. The alliance consisted of five organizations: the public sector client and four large international engineering consultant companies, each with their designated field of expertise. The alliance was initially contracted to a program of seven geographically distinct construction projects. An alliance leadership team was constituted to ensure consistency and learning across the different projects.

In this study we focus solely on the practicing of the Alliance Leadership Team (ALT), a governance team of senior executives representing each of the parent organizations, The ALT has a strategic advisory as well as a financially decisive role, meeting regularly on a monthly basis. Each member of the ALT is a champion for specific aspects of the program, with shifting roles and responsibilities, working closely with a number of employees across all levels of the alliance.

\section{The Empirical Material}

The main source of empirical material is participatory observation. From 2002 up to and including May 2007 one or more researchers sat in on and observed the Alliance Leadership Team's monthly meetings. Additionally, a range of informal meetings and 
discussions with ALT members prior to and after the scheduled meetings occurred. We conducted 24 semi-structured interviews focusing on how people understood and made sense of the meaning of their work in the context of the alliance. All the interviews were performed by two researchers, in order to provide a better basis for critical reflection in the interpretative phases of the research. In addition, large samples of secondary data, such as financial reports, managerial reports, official media and alliance documents and policy documents were collected. The researchers also visited all the current and past construction schemes in conjunction with the ALT meetings, and three workshops were held with the ALT, in which ongoing findings were presented and discussed.

\section{The Analysis}

All authors were involved in analysis of empirical materials. Although starting our interpretations from similar epistemological and ontological outlooks we found surprising differences in our emphasis on stable and changing features of the practice in question: Where one researcher would emphasise the normative continuum as participants changed, another might emphasise the fluidity of norms despite the stability of participants. Acknowledging that our periods of observation situated our interpretations in the particulars of that period, we re-evaluated the empirical material by focusing on the temporal changes and on traces of stability. Field notes were re-read and re-interpreted with a more temporal horizon in mind. The discussions and re-evaluation based on these initial interpretations gave us the constructs of becoming (a) practice that we present in this paper. Material from the overall research collaboration provides the horizon against which the interpretation of Alliance Leadership Team’s practicing was constructed. 


\section{Findings and Interpretations}

At the outset of the Alliance Program the Alliance Leadership Team was introduced as a new organizational level within alliance collaboration. The ALT's task would be to see that the different projects in the program were coordinated, to make strategic decisions on behalf of the alliance, and carry the final responsibility for the performance of the alliance. Initializing the alliance program, several documents governing the alliance work were constructed. These documents served as the starting ground for the collaborative work of the ALT and the ALT participants situated these initializing constructs in (a) practice as their work and time passed.

Our interpretation of the empirical material suggests three important mechanisms in the becoming of (a) practice: First: Authoring Boundaries; processes by which activities are constructed as legitimate part of practicing (or not). Second: Negotiating Competencies, processes by which practicing, and practitioners, are constructed as competent, Third: Adapting Materiality, the processes by which material configurations are enacted and entangled in practicing and constructed as essential elements of (a) practice. 


\begin{tabular}{|c|c|c|c|}
\hline & Initializing constructs & Constructs of a practice & Explanatory constructs \\
\hline $\begin{array}{l}\text { Authoring boundaries } \\
\text { - What is legitimate } \\
\text { practice? } \\
\text { How would practice } \\
\text { deviate from } \\
\text { legitmacy? }\end{array}$ & $\begin{array}{ll}\text { - } & \text { Contractual } \\
\text { agreement } \\
\text { - } & \text { Sharing risks and } \\
& \text { rewards } \\
\text { - } & \text { Equal partners }\end{array}$ & $\begin{array}{ll}\text { - } & \text { Unanimous decisions, } \\
\text { - } & \text { Trust and face value } \\
\text { discussions } \\
\text { - } & \text { Experts and novices } \\
\text { (inside and outside) }\end{array}$ & $\begin{array}{l}\text { - } \quad \text { Practicing an informal web } \\
\text { of knowing what-to; from } \\
\text { questioning ways of } \\
\text { performing to established } \\
\text { ways of doing } \\
\text { - Constructing a practical } \\
\text { "ideal speech situation" }\end{array}$ \\
\hline $\begin{array}{l}\text { Negotiating } \\
\text { competencies } \\
\text { - What does it take to } \\
\text { perform as a } \\
\text { competent } \\
\text { practitioner? }\end{array}$ & $\begin{array}{l}\text { - List of goals and } \\
\text { measurements }\end{array}$ & $\begin{array}{l}\text { - } \quad \begin{array}{l}\text { Negotiation of goals and } \\
\text { measurements }\end{array} \\
\text { mas }\end{array}$ & $\begin{array}{l}\text { - Emphasizes the } \\
\text { situatedness of knowing and } \\
\text { the social construction of a } \\
\text { practice }\end{array}$ \\
\hline $\begin{array}{l}\text { Adapting Mate riality } \\
\text { - Through what } \\
\text { devices are practices } \\
\text { materialized? }\end{array}$ & $\begin{array}{ll}\text { - } & \text { Project plans, } \\
\text { budgets etc } \\
\text { - } \quad \text { Set time and task } \\
\text { for collaboration }\end{array}$ & $\begin{array}{l}\text { - Affirming their new } \\
\text { approach to construction } \\
\text { management through } \\
\text { site visits, } \\
\text { representational } \\
\text { strategies, and meeting } \\
\text { protocols } \\
\text { - Ong oing achievement }\end{array}$ & $\begin{array}{l}\text { - Affirming the significance of } \\
\text { the site as the place in } \\
\text { which their symbolic work } \\
\text { gets done } \\
\text { - The site as a "sacred place" } \\
\text { of/for practice } \\
\text { - } \quad \text { ifting the practicing from } \\
\text { particular performances to } \\
\text { generalized patterns . }\end{array}$ \\
\hline
\end{tabular}

Table 1 - summarizing the initial constructs of formal collaborative rules, the constructs of the practice, and the researchers’ explanatory constructs.

Table 1 illustrate the becoming of the practices investigated. "Initializing Constructs” represent the formal constructs establishing the starting point for the ALT's work. Becoming a practice entails the uncertainty of the new even as it draws on the multiplicity of the old. The participants engaged in particular practices' becoming are, of course, participants in a wide range of other practices, which they draw on in establishing a new practice. While few practices are initialized as formal collaborations, these constructs were what brought our practitioners together to work, thus serving as their initializing constructs. "Constructs of a practice” presents ways in which the ALT were practicing as our research ended. While the constructs of a practice carry traces of the initializing constructs, they are no longer formal, there are constructs added and removed, and they seem driven by social rather then economic or institutional forces. The last 
column, "explanatory constructs", contain the constructs that we used as researchers to explain the changes observed.

In the following we will discuss how the Alliance Leadership Team's practicing evolved, moving from the initializing constructs of formal rules on how to work together, to a set of informal constructs of practice. The constructs we present are labelled as such because of the dualism of their constructed origin. First; they are constructed in and of practice, as sets of accepted ways of acting in and on practices by the practitioners, second; they are re-constructed by us, the researchers, as we describe the practicing, freezing this practice in our writing and (re-)constructing of it.

\section{Authoring Boundaries}

As Schatzki (2001) emphasised, practices are considered to be embodied arrays of activities organized around more or less shared practical understandings, "ways of doing”, or performing. Such understandings will constantly be negotiated for all practicing is at the same time a performance of a particular practice, reinforcing or breaching expectations, negotiating what it is to be practicing something specific. When practices are established it is fairly easy, at least for the insider, to know whether a practitioner is practicing the practice; if a vegetarian is eating meat, s/he is not practicing vegetarianism, if a soccer player is touching the ball with his hands during the game s/he is not practicing football (unless s/he is the goalkeeper). When investigating practices of becoming, the fluid, constant construction of norms becomes vivid because the rules of the game have not been stabilized. What it takes to be practicing is still in the making. In set practices these negotiations are explicitly performed through sanctioning breaching of 
rules, thus reinforcing and diminishing specific interpretations. Less evidently but more often these negotiations also takes place through silent legitimization of the multitude of possible ways practices are performed.

There were several initializing constructs guiding the work to be performed by the Alliance Leadership Team; the most important was the Alliance Program Contract. Included in the contractual agreements were issues of sharing of risk and rewards, of the partners being constituted as equal participants in the collaboration, as well as a set collection of tasks comprising seven construction projects. Contrary to traditional design and construct contracts the alliance program contract is best signified through its relative lack of presence, both in terms of size and use: "an ideal alliance contract is one page long, read, signed, and put in the drawer never to be looked at again” (General Manager, Public Partner). In the initial phases of the ALT's work, the contract represented a formal authority on right and wrong conduct in terms of alliancing, constituting a formal authoring of boundaries within which to perform. Contrary to traditional design and construct contracts that tend to attract both appreciative and exploitative enquiry throughout a construction project, continuously including new variances and additions, this contract remained literally untouched.

Throughout the program we noticed that, over time, the discussions and negotiations in the Alliance Leadership Team changed character. Initially the members were evidently participants from different organizations, meeting to negotiate the collaboration on behalf of these. Through a slow process of small changes the ALT is now practicing as a collective of indiscernible partners, at least with respect to company background. ALT 
members always seem to be talking on behalf of the Alliance Leadership Team. Interestingly, for one of the researchers who joined the project in the later stages of the alliance it was literally impossible to distinguish the parent companies of the different members of the ALT. Moreover, two separate consulting firms worked with the alliance on different aspects of the project; during informal discussion that we had with them they relayed the same observations to us, with one consultant observing "I can't tell who is with what company".

The construction of relatively stable patterns of interaction became more evident as deviation from anticipated practice started to receive explicit sanctioning: In the latter parts of the research a new ALT participant, from one of the contracted engineering companies, was introduced to the group. During a discussion on bonus payments, it was stated that all decision by the ALT must be unanimous. The new ALT participant questioned the 'decision' that no decisions should be made unless they were made unanimously. The rest of the participants looked at him in a stunned way, clearly indicating that this was an awkward question, almost blasphemous. Here was a clear example of a clash of expectations and the response by the ALT was fascinating and remarkable. In response to such a 'naive' observation regarding unanimity, one of the ALT members said: "This is what alliancing is! That's part of alliancing”. The novice responded: “Don’t you mean consensus? [rather than unanimity]”, only to have someone else say: "We may discuss it till we find consensus, but we have no decisions at the [Alliance Leadership Team] unless they are unanimous!” The novice looked utterly stunned. All the others nodded in agreement with the experienced team member. The 'we' was clearly a significant marker of identity. 
One of the key phenomenologically agreed contours of sensemaking of the ALT seems to be that they should govern democratically, by unanimous decision. Interestingly, without any intellectual knowledge of Habermas’ (1979) 'ideal speech situation’ or Rawls’ (1971) 'original position’, the Alliance Leadership Team seemingly strove to achieve something close to these models. The common building block in this and other events was the repeated reference (in speech and other acts) to the alliance 'we'. That such a collective voice is created should not be too surprising, considering that the Alliance Leadership Team defined itself as negotiating such a collective 'we' on behalf of a set of independent organizations. More surprising however is the emphasis on unanimity which certainly does not find a parallel in the normal design and construct contracts. Neither does it seem to find a parallel in many ordinary organizational leadership teams: consensus perhaps, but not total unanimity.

Observing the practicing of the Alliance Leadership Team, we see that they move from categorising their work as being performed by an alliance, with its formal boundaries and rules of collaboration, to describing their work as "alliancing"; the practicing of a certain way of doing, a certain way that is not stated in contracts and plans, but constantly authored in the warp and weft of their practicing. In the initial phases of the alliance program the formal contract, the participants' experiences with previous construction projects (alliances as well as design and construct projects), and their anticipations of alliances were guiding the discussions and decisions and used as reference for right and wrong course of actions. The current situation is quite changed; it is one in which the ALT's own practicing has become a point of reference, constructing the boundaries by which right and wrong actions are judged. We suggest the boundaries of legitimate 
actions are continuously constructing the practice of the ALT while their practicing is simultaneously authoring the boundaries of legitimate actions.

\section{Negotiating Competencies}

Negotiating Competencies refers to the processes by which activities are constructed as competently performed or not. While Authoring Boundaries constitute processes in which activities are authored as falling inside or outside the becoming practice, here competence is negotiated with respect to activities constructed as belonging. These processes are analytically separated, and while some, such as the ones chosen for presentation in this paper, easily fall into the one construct or the other, we will not disguise that there are numerous activities in greyer shades.

The initialising constructs used in negotiating competencies by the Alliance Leadership Team were the Key Performance Indicator's (KPIs): Cost, schedule, safety, environment and community communication. The Alliance Program as a whole aimed to enhance the environment through connecting a number of communities without regular sewerage to a central sewerage cleaning system. Such a project is highly environmentally charged in terms of the potential for contamination of the local environment, as it occurred in remote communities proximate to areas of pristine natural ecology. Moreover, the project is highly intrusive on the local communities in which it is performed because the project has to be partially executed on local citizens' properties; further, each household will now be expected to pay for the services provided through the construction project. While cost, schedule and safety measurements are traditional measures of quality in construction projects at large, the equal importance put on environment and community 
communication is a particular of the Alliance Program approach as it has developed between the partners.

The Alliance Leadership Team initially decided that the target measurements for Business as Usual (BAU) on the KPI's should be comparable to Outstanding Performance (OP) in comparable construction projects and to set OP targets at an innovatively high level. Consequently the ALT constructed a high limit for the program with respect to the performance levels defined as the threshold for achieving the rewards and bonuses tied to outstanding performance. In these initial sensemaking processes the Alliance Leadership Team participants negotiated a collective drive and purpose to collaborate, premised on a deep desire to be outstanding. We refer to this in what follows as the 'ideal we'.

Since the outset of the Alliance Program the formal initializing constructs have been a centre of attention in most Alliance Leadership Team Meetings. Below is a transcript of a discussion that reflects the negotiation of KPI's that frequently takes place. The issue at stake is the Business As Usual and Outstanding Performance measures concerning the publics' connection to the service provided. The BAU is set very high, at $97 \%$. The KPI turns out to be hard to nail while the ALT's perception is that the connection rates they have achieved actually reflect outstanding performance:

- $\quad$ G: We have a $97 \%$ connection rate, and this is [only] Business as Usual

- $\quad$ H: Maybe it is time to review some of these, they seem unrealistic

- G: But will we be perceived as soft [by the contractor] if we do that?

- I: We could loosen up on some, and tighten others; it is just that [the KPIs] are unachievable as they are.

- $\quad$ J: I think we should reconsider it for the next schemes, and make the KPIs dependent on the slots and sites, and the likelihood of connections at different sites

- I: Yes, it is not about getting it soft

- G: If the target is unrealistic it does not drive the behaviour that we want. 
- $\quad$ H: The behaviour that we want is something that takes the community into account, so that these will connect due to this process. But is there really correlations, can we really affect it?

- $\quad$ G: If there is high cost or trouble to the consumer, if they have an already functioning system, they will not connect however happy they are with us.

- $\quad \mathrm{H}$ : Well it will be valuable data to know why [the consumers] are not connecting...

- J: ...If [the connection] is beyond our control.

- H: If there is someone that should definitely not connect, they should not be part of the connection rate. The connection rates are percentages of those that we could possibly assume would connect.

- J: Australian standard is that the personal lines are not acceptable. However, if we do tests and see that the lines are not bleeding, why should we make people connect?

Such explicit negotiation of the competence markers takes a considerable amount of the Alliance Leadership Team's time. We suggest the above transcript as one instance of the continuous negotiating of competencies we see in the ALT. Note that the discussion is not about the actual scores that discriminate between the different targets. To achieve 97\% connection is the Business As Usual target; above this is Outstanding Performance. The ALT seems to accept that their performance will be judged, both by themselves and by significant others, according to the numbers they achieve.

Given that the ALT is responsible for the overall performance of the Alliance Program, a wide range of different interpretations could be given of these events: we could say that they are deeply involved in the hypocrisy of organizing (Brunsson, 2002); that they are demonstrating leadership in change management (Sullivan et al. 2001), or we may even say we are observing a classic case of what psychologists call cognitive dissonance (Festinger, 1957), where there are simultaneously occurring but conflicting cognitions, experienced at the level of the 'ideal we' rather than the individual. These explanations, however, attribute intentions to the members of the Alliance Leadership Team, intentions that they have not confirmed, intentions that may or may not be 'right', may or may not be constructed, narrated or rationalised and, not to forget, intentions that may very well 
vary greatly between the different members of the ALT. Furthermore, what is most significant in these processes of sensemaking in the ALT is not driven by any inner springs of intentionality forged in the harsh world of commercialism but seems bathed in the pure ether and bathos of the Alliance Leadership Team’s ‘ideal we'. Rhetoric eclipses normal subject positions as unanimity is expressed discursively.

The Alliance Leadership Team continuously negotiates how they could and should translate the work done so that the measurable performance of the Alliance Program work expresses the ideal or outstanding construction projects that the ALT aspires to lead. In these discussions we see that the relation between the practice and the KPIs (the performance is outstanding) is constant. The discussions concern how to validate the measurements so that the Outstanding Performance of the Alliance Program, the ALT's area of responsibility, can be communicated to external others and to the collective self. Thus, rather than question the number, they negotiate how their excellence should be represented in this number. They are not negotiating whether they are mastering something but what it is to be seen to be mastering it in what they are doing, so they can demonstrate to others that they are doing mastery. In a language game perspective the rule and the mastering of it is one and the same: the negotiation of competencies we see in the ALT's practicing is such that the very negotiation instantiates competent practicing.

In practice-based theories negotiation of competence is more often referred to in relation to social configurations and (individual) positioning (Wenger, 1998, p 197), than constructing aspect of practice. Studying an emerging practice, however, enables us to 
emphasise the becomingness of the rules, and highlights that while competence is necessary to performing a practice well, practice also constructs what is competence. Competence and practice are mutually dependent constructs, constantly negotiated through practicing.

\section{Adapting Materiality}

In practice theory apprehension of a specific practice's material configurations are generally put forward as essential to understanding this practice (Schatzki, 2001), where material configurations are coined both by reference to the immediate material settings of the activities explored and also to the larger context by which the practice plays a part and makes sense within.

Contracts, plans and budgets, discussions on deviations and variations and distribution of responsibility are concerns of material importance in the management of traditional design and construct projects, where the participants' companies may be fighting for mutually exclusive profits and costs. In the work of the Alliance Leadership Team however, signs of such fragmented materiality were fast overturned. The participants in the ALT seem to be continuously constructing an alternative materiality, materializing practice at different levels. First, the ALT embeds the materiality of the construction site in their practicing, a setting not usually immediately present in strategic management work. Second, the ALT is continuously constructing an overarching context in which they place their collaborative work; the battle for a better environment and, more particularly, the cleaning and greening of New South Wales' coast line and waterways. 
Consider the materiality constructed through the Alliance Leadership Team's choice of meeting venues: While all the ALT members have offices in Sydney's Central Business District (CBD), and the construction sites are scattered around New South Wales (often as long as two hours drives from CBD), the ALT moved their collaborative work out of the board room, onto the construction sites. The change in venues were not explicitly decided but implicitly agreed as "the way we do things", with the participants noting that being at the sites is crucial to "get the feel of the project, one glimpse at the construction site and you can see if it is run well or not, you know: Is it tidy? Can you see what is going on? - It is important, it is like a health check” (ALT Member). Through closeness to the site they seem actively to be materializing their own practice, moving from their traditional roles as competing business managers, by constructing space for the practice of collaborative construction management, of alliancing. Adapting Materiality not only takes place with respect to choice of meeting venues but is reflected in their way of talking of their work, the topics given time at the meetings, the choices of artefacts presented in meetings, and so on. We suggest that the ALT is constructing the site as a 'sacred site' of/for practice, and that the sacred sites also offer affirmation with respect to their work - their practicing is materializing through the construction site as work is done, nails are hammered, formwork built, trenches dug, concrete poured, and water cleaned. The practice is becoming in relation to very tangible, material activity.

In practice theory the material aspects of practicing is predominantly investigated with respect to the tools that the practitioners are handling (Håkonsen, 2007): the hot iron of the blacksmith (Keller and Keller 1993), the sketches and drawings of laboratory work (Latour and Woolgar (1979), or the utilization and interactive forming of information and 
communication technology (Orlikowski and Hofman, 1997). What we are suggesting here, however, is that the Alliance Leadership Team materializes their practice through appropriating other's immediate materiality. Initialising the construction program, and the ALT's collaborative work, the project plans and budgets appear as the sole material configurations of the work to be performed; the board room might normally appear to be the natural place in which to execute such activity. The ALT members, however, quickly chose to arrange their meetings at the construction sites, which they initially rationalised through ideas of "inspection”, "getting an overview". Later, they met on site not to get an overview or perform an inspection but, in their own words, to construct the sewerage systems. We see a change in the ALT members' rationalizing of their activities. We suggest that the materiality of the site deeply affects the ALT members' work practices. By giving shapes, smells, and sounds to the practices, close to the constantly changing nature of the construction sites and the becoming into being of the sewerage cleaning systems, they create in and by practice a rationality that is heavily situated in construction site practice.

The situatedness of rationality is also evident in discussions about continuance of the alliance's work: according to the participants, the proportion of time spent in the Alliance Leadership Team greatly overshadows the financial outcome of the project. Also, none of the parent companies are in need of the alliance; there is a shortage of engineers in Australia due to a resources boom, meaning companies constantly have a hard time filling project positions. In many ways the project is an imposition on the organizations involved. Nevertheless, the participants in the ALT are actively pursuing new projects for the alliance to perform together. Asking for the reasoning for this drive for 
continuation of the alliance, no clear answers are given. It seems as if the alliancing they are practicing has attained a material objective status, acting as a cause for its continuation as a practice in itself.

Practices are always embedded. Established practices act as passage points to new practices; they are simultaneously gateways and conduits but also channels and kerbing that direct the flow of learning. Exploring practicing in light of emergence rather than embeddedness does, however, allow us to emphasise how actors strive to make sense of themselves and their world at the same time as they are constructing it in their work. We have suggested three central mechanisms in the becoming of (a) practice. First, Authoring Boundaries, involving the members of the Alliance Leadership Team constructing formal and informal boundaries of practice, thus enabling them to perform and to identify activities as either inside or outside the particular practice which they collaboratively constructed themselves to be a part of. Second: Negotiating Competencies. A central, explicit, and reoccurring theme in the ALT's meetings, one that was continuously up for negotiation and reinterpretation, was the issue of good performance and competent practicing. We saw knowledge and knowing continuously constructed and situated in and through the becoming of (a) practice. Third: Adapting Materiality: the formal work of the ALT was initially firmly situated in the board room; however, their practicing was actively grounded in the materiality of the construction site and inherently meaningful in that context. These three mechanisms have in common that through practice they are constructed as stable yet are simultaneously continuously changing, thus continuously constructing practice. Knowledge, knowing, and goals are not shared and stable entities; 
they are continuously constructed; authored, negotiated and adapted. Stability is thus a construct perceived through continuous becoming.

\section{Conclusion}

People make sense as they act upon their world and, typically, accept new practices insofar as they do not contradict their taken-for-granted knowing of what constitutes appropriate practice. The forming of a practice coming-into-being is always constituting and reconstituting itself: it is becoming per se. Practicing, therefore, in relation to becoming, is tentative and ongoing. As Kornberger et al (2005) argue, in accord with Tsoukas and Chia (2002), practicing is not merely a process punctuated by events, it is a movement that develops and unfolds through the intensity of connections that drive the process of becoming. The constructs presented here are merely these processes punctuated by our attempt to display them. By presenting them they become "something", frozen in the moment, and dependent on our insistence on them as ongoing and changing.

With Garfinkel (1967), we would argue that the analysts' task is to formulate the rules underlying everyday conduct, including that which is only becoming what it has yet to be taken to be. Following Schütz (1967), this should be done in terms that can be translated back to the practitioners of that practice such they are able to see themselves in these terms. Where Garfinkel (1967) emphasises breaching events to get the sense of what is and is not a routine practice, we suggest that any practice studied in its novelty represents a breach with traditional practice and can be used as a stepping stone to saying something about how practices 'become into being' as well as the evolution of practices specifically. 
Shocks, according to Schütz (1967), are glimpses into other possible worlds of reality. Quite literally, shock refers to the sometimes brief realization that the world can be experienced in ways beyond the taken-for-granted meanings that construct our experience of it. For an outsider, unused to alliancing practice, what we have observed would certainly seem surprising and might even be shocking. For our practitioners, the mirroring of their activities as a practice; with slow moving do's and don'ts (authoring boundaries), continuous juggling of measurements (negotiating competencies), and a living cause of action (adapting materiality) was recognised and shocking - both in terms of what became, and what could have come.

It would be easy - and too facile - to say that the Alliance Leadership Team were institutional entrepreneurs. Recalling DiMaggio's (1988) initial definition "new institutions arise when organized actors with sufficient resources see in them an opportunity to realize interests that they value highly...[Institutional entrepreneurs] create a whole new system of meaning that ties the functioning of disparate sets of institutions together (DiMaggio 1988: 14), the ALT is creating a new system of meaning, bootstrapping it in their practice, but not, as it were, to institutionalize interests that are valued highly a priori. Instead, what we see are interests being constructed to fit the institutional practice that is becoming into being. There is a reversal of causal logic; bootstrapping the institution leads to the interests emerging - as we see clearly in the novice's introduction to unanimous decision-making. Fundamentally, the ALT would agree that they have found a better way of doing construction than the typical practice of design and construct contracts in which the main project is not just accomplishing the design but doing so on the most advantageous terms to the organization one represents - 
and that means screwing as much indexicality as one can out of the contract (Clegg 1975). Perhaps, in their own way, these actors have hit upon a Habermasian (1979) commitment to open and free communication and find it more agreeable than the dog-eatdog world that they usually move in. We have not yet asked them, and would have to do a great deal of translation to do so, but it is the thought that we would like to leave with readers of this paper: Through practicing we may become better in ways that we might never have institutionally imagined, a priori.

\section{References}

Althusser, L. (1969) For Marx. London: Allen Lane

Blum A. F. and McHugh P. (1971) 'The Social Ascription of Motives', American Sociological Review 36:98-109.

Brunsson, N. (2002) The Organization of Hypocrisy: Talk, Decisions and Actions in Organizations, Stockholm: Abstrakt forlag AS

Clegg, S. R. (1975) Power, Rule and Domination, London: Routledge and Kegan Paul.

Clegg, S. R., Pitsis, T. S., Rura-Polley, T., and Marosszeky, M (2002) ‘Governmentality Matters: Designing an Alliance Culture of Inter-organizational Collaboration for Managing Projects’, Organization Studies, 23 (3): 317-337.

Clegg, S. R., Kornberger, M., and Pitsis, T. (2008) Managing and Organizations (2nd edition), London: Sage 
DiMaggio, P. (1998) 'Interest and agency in institutional theory’. In L. G. Zucker (ed.) Institutional patterns and organizations, pp.3-22, Cambridge, MA: Bellinger.

Festinger, L. (1957). A theory of cognitive dissonance. Stanford, CA: Stanford University Press.

Garfinkel, H. (1967). Studies in ethnomethodology. Englewood Cliffs, NJ: Prentice Hall

Gherardi S., and Nicolini, D (2003) 'To Transfer is to Transform: The Circulation of Safety Knowledge' in D. Nicolini, S. Gherardi, and D. Yanow. (eds): Knowing in Organizations. A Practice-Based Approach. London: M. E. Sharpe.

Gomez, Bouty, M-L, I. and Drucker-Godard, C. (2003) 'Developing Knowing in Practice, Behind the Scene of Haute Cuisine' in D. Nicolini, S. Gherardi, and D. Yanow. (eds): Knowing in Organizations. A Practice-Based Approach. London: M. E. Sharpe.

Habermas, J. (1979) Communication and the Evolution of Society. Translated by Thomas McCarthy. Boston: Beacon Press.

Håkonsen, G. (2007) Making a difference: Creative dialogues, protopratice and the moral shaping of knowledge in a media company. Doctoral theses at NTNU, 2007:116 Norwegian University of Science and technology. Faculty of Arts. Department of Interdisciplinary studies of culture 
Keller, C and Keller, J:D (1993): 'Thinking and acting with iron' in Chaiklin, S., and Lave, J. (eds.). Understanding practice: Perspectives on activity and context. Cambridge: Cambridge University Press.

Kornberger, M, Clegg, S. R. and Rhodes, C., (2005) 'Learning/Becoming/Organizing', Organization, 12(2): 147-167.

Latour, B. and Woolgar, S. (1979). Laboratory Life : The Construction of Scientific Facts. Thousand Oaks: CA: SAGE.,

Mills, C. W. (2002) 'Situated actions and vocabularies of motive', pp. 183-192 in S. R. Clegg (ed.), Central Currents in Organization Studies II: Contemporary Trends, Volume 6. London: Sage; originally published in American Sociological Review (1940) 5: 904-913.

Munro, R. (2008) ‘Actor network theory', forthcoming in Clegg, S. R \& Haugaard, M. (eds) Handbook of Power, London: Sage.

Nicolini, D Gherardi, S. and Yanow, D. (2003) 'Introduction: toward a Practice Based view of Knowing and Learning in Organizations.' in D. Nicolini, S. Gherardi, and D. Yanow. (eds): Knowing in Organizations. A Practice-Based Approach. London: M. E. Sharpe.

Orlikowski, W.J. and Hofman, J D (1997) 'An improvisational model for change management: the case of groupware technologies'. Sloan Management Review 
Pitsis, T. S., Clegg, S. R., Marosszeky, M., and Rura-Polley, T (2003) 'Constructing the Olympic Dream: A Future Perfect Strategy of Project Management', Organization Science 14 (5): 574-590.

Pitsis, T. S., Kornberger, M., and Clegg, S. R. (2004) 'The Art of Managing Relationships in Interorganizational Collaboration’ Management, 7 (3): 47-67.

Rawls, J. (1971) A Theory of Justice, Cambridge: Harvard University Press.

Schatzki, T. R. (2001) 'Introduction; Practice Theory’ in T. R. Schatzki, K. Knorr Cetina and E. Von Savigny (eds) The Practice Turn in Contemporary Theory. London: Routledge

Schütz , A (1967) The Phenomenology of the Social World. Translated by G. Walsh and F. Lehnert. Ill. Northwestern University Press

Suchman, L (2003) 'Organization Alignment: the Case of Bridge Building' in D. Nicolini, S. Gherardi, and D. Yanow. (eds): Knowing in Organizations. A PracticeBased Approach. London: M. E. Sharpe.

Sullivan, Wendy, Sullivan, Robert and Buffton, Barbara (2001) 'Aligning individual and organisational values to support change', Journal of Change Management,2:3,247 254

Tsoukas H. \& R. Chia (2002) 'On organizational becoming: rethinking organizational change’ Organization Science, 13: 5, Sep.-Oct., 2002, pp. 567-582. 
Weick, K.E., Sensemaking in organizations, Sage Publications, Inc.

Wenger, E. (1998) Communities of Practice: Learning, Meaning, and Identity. Cambridge, UK: Cambridge University Press.

Wittgenstein, L. (1953) Philosophical investigations. Oxford: Blackwell.

Yanow D, (2003), 'Seeing Organizational Learning, A “Cultural” View’ in D. Nicolini, S. Gherardi, and D. Yanow. (eds): Knowing in Organizations. A Practice-Based Approach. London: M. E. Sharpe. 